\title{
Feasibility and effectiveness of supplementation with locally available foods in prevention of child malnutrition in Kenya
}

\author{
Angelo Tomedi ${ }^{1}$, Felisha Rohan-Minjares ${ }^{1, *}$, Kate McCalmont ${ }^{2}$, Rebecca Ashton ${ }^{2}$, \\ Rose Opiyo ${ }^{3}$ and Mutuku Mwanthi ${ }^{3}$ \\ 'Department of Family and Community Medicine, University of New Mexico Health Sciences Center, \\ 2400 Tucker Street NE, Albuquerque, NM 87131, USA: ${ }^{2}$ University of New Mexico School of Medicine, \\ 1 University of New Mexico, Albuquerque, NM, USA: ${ }^{3}$ Department of Community Health, University of Nairobi, \\ Kenyatta National Hospital, Nairobi, Kenya
}

Submitted 24 November 2010: Accepted 29 July 2011: First published online 6 September 2011

\begin{abstract}
Objective: To establish the operational feasibility and effectiveness of using locally available foods to prevent malnutrition and improve child growth in Kenyan children. Design: Quasi-experimental design with an intervention group of children in all villages in one region and a non-intervention group of children in all villages in an adjacent region. The intervention was the distribution of a monthly food ration for the index child, a separate family ration, and group education on appropriate complementary feeding and hygiene.

Setting: Rural villages in the arid lands of eastern Kenya with a high prevalence of child malnutrition.

Subjects: All children in the target villages aged 6-20 months with weight-forlength $Z$-score (WHZ) greater than -2 at baseline.

Results: Children in the intervention and non-intervention groups had similar baseline anthropometric measures. The caregivers in the intervention group confirmed that the intended amounts of food supplements were received and child nutrient intake improved. During the 7-month intervention period there were significant group differences in pre-post $Z$-score changes between the intervention and non-intervention groups for weight-for-age $(0 \cdot 82, P<0 \cdot 001)$ and weight-for-height $(1 \cdot 19, P<0 \cdot 001)$, but not for height-for-age $(-0 \cdot 20$, $P=0 \cdot 09)$, after adjusting for multiple covariates. Compared with the non-intervention group, the intervention group had a lower prevalence of wasting ( $0 \% v .8 .9 \%$, $P=0 \cdot 0002)$ and underweight $(6 \cdot 3 \% v .23 \cdot 0 \%, P<0 \cdot 0001)$. Infectious morbidity was similar in both groups.

Conclusions: The findings suggest that the distribution of locally available foods is operationally feasible and improves child weight gain and decreases acute malnutrition in Kenyan children.
\end{abstract}

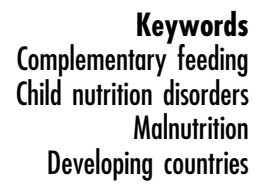

Child malnutrition impairs physical and neurological development and is a major cause of child mortality ${ }^{(1)}$. The prevalence of child malnutrition is high in many developing countries, particularly in Sub-Saharan Africa ${ }^{(1)}$. In Kenya, $16 \%$ of children under 5 years of age are underweight (weight-for-age $Z$-score (WAZ) less than -2 ) and 35\% are growth stunted (height-for-age $Z$-score (HAZ) less than -2 ). The proportion of growth stunted children is highest ( $42 \%$ ) in Kenya's Eastern Province, the site of the present study ${ }^{(2)}$.

Bwibo and Neumann ${ }^{(3)}$ have summarized food intake and nutrition studies conducted in Eastern Province of Kenya. The diet is maize-based and children are commonly fed a porridge made from maize flour with a low energy density. The growth of young children falters as early as 3-4 months of age. Animal-source foods, which the WHO guidelines recommend be eaten daily or as often as possible ${ }^{(4)}$, are rarely fed to the children.

Many large-scale food aid and relief programmes and efficacy studies have attempted to address the problem of child malnutrition. Most programmes and studies have selected malnourished children as the target population, or have included children with malnutrition in their sample. There is a paucity of studies on the prevention of this devastating problem. The aid and relief programmes in Sub-Saharan Africa usually distribute a commercially prepared fortified maize-soya or wheat-soya blend, often with vegetable oil, to vulnerable populations of young children $^{(5)}$. The intent is to reduce the high rate of child malnutrition in these populations, although the effectiveness of this approach has been questioned ${ }^{(6-8)}$. A review of 
the efficacy and effectiveness studies of interventions designed to improve complementary feeding found inconsistent results, with a positive impact on child growth in some studies and no impact in others ${ }^{(9)}$. As in large-scale relief efforts, most studies used a commercially prepared fortified product or vitamin/mineral fortification alone.

The disadvantages of the provision of processed cereallegume blends and other commercially prepared products include the expense and the lack of availability when donors withdraw their support. When the programme ends, the mothers/caregivers are very likely to revert to feeding the same local complementary foods. Distribution of local foods combined with an education programme could potentially avoid this problem. However, the problem of 'leakage', or the sharing of the food supplements with other family members, could negate the benefits of the food distribution, as was reported in a Brazilian study of a milk supplement ${ }^{(10)}$. In regions of chronic food insecurity, the distribution of local foods will only be a temporary measure until local production (or income) improves. The distribution programme, however, has the potential to improve local production, as demonstrated by the milk distribution programme in Chile that had the eventual effect of stimulating the development of a dairy industry ${ }^{(11)}$. More research is needed to study the feasibility of the approach of providing adequate quantities of local foods to improve complementary feeding in high-risk populations and its effect on the prevention of child malnutrition.

In response to a recent drought in Kenya that worsened food insecurity and increased child malnutrition, a project was initiated by a non-governmental organization to screen a population in Eastern Province for acute malnutrition and provide treatment. Villages in this region were chosen for the present study of the operational feasibility and effectiveness of the distribution of locally available foods to prevent malnutrition and improve child growth. Infectious morbidity was also included as an outcome. The treatment of acute malnutrition was arranged through a separate programme.

\section{Methods}

\section{Study site and participants}

The study sites were in Yatta District of Eastern Province, Kenya. The Kamba ethnic group includes subsistence farmers who rely on rain-fed agriculture. The main crops are maize and beans, which are the staple foods, as well as cowpeas and pigeon peas. Small-scale horticulture and animal husbandry are also practised. Kenya experienced an extended period of drought that began in 2007 and resulted in crop losses and increased food prices.

In response to an increase in child malnutrition, Global Health Partnerships, a non-governmental organization that supports a health clinic in the district, funded a village-based screening of the households in one location (population approximately 15000) to detect and treat pre-school children with acute malnutrition (wasting), defined as weight-for-height Z-score (WHZ) less than -2 . The location is divided into two geographic sub-locations (as designated by the Government of Kenya) of approximately equal population. One sub-location of twenty villages was selected for the intervention, and the other (adjacent) sub-location served as the non-intervention group. Both sub-locations are governed by the same local chief and have community health workers (CHW) who participate in the screening of the households with children under 5 years of age for acute malnutrition. For the present study, all children who lived in the two target sub-locations were eligible to participate if they were 6-20 months of age at the onset of the study and had WHZ $\geq-2$. The local CHW volunteered to assist with the food distribution and identification of the children for the study. The age group 6-20 months was selected because of evidence that children at this age are most vulnerable to the physical and mental adverse effects of undernutrition ${ }^{(12)}$ and the potential benefit from supplementation is greatest ${ }^{(13,14)}$. The children with $\mathrm{WHZ}<-2$ were enrolled into a community-based therapeutic feeding programme and were excluded from the study. The study protocol was approved by the Human Research Review Committee of the University of New Mexico and the Kenya Ministry of Science and Technology review committee. Permission to carry out the study in Yatta District was obtained from the District Health Management Team and informed consent was obtained from a parent or guardian of each child.

\section{Study design}

A quasi-experimental design was chosen with an intervention group consisting of all villages in one sub-location and a non-intervention comparison group consisting of all villages in the adjacent sub-location. Random allocation of villages to intervention (food supplementation) and control (no food supplementation) groups was not considered ethical or acceptable by community leaders during this time of drought and food insecurity in Kenya. In addition, the organization that initiated the food distribution programme was only able to provide funding for the villages of one sublocation. Thus, the site of the intervention was intentionally chosen because it included the villages with the highest rate of malnutrition during a survey that was conducted in March 2009. The adjacent sub-location was chosen as a non-intervention group because anthropometric data were collected as part of a malnutrition screening project during the same month as the intervention group baseline data and this could serve as baseline data. Furthermore, the Kenyan coordinator and collaborators had the impression that the households in the adjacent non-intervention sub-location had similar characteristics to the intervention group.

In November 2009, the CHW identified every child aged 6-20 months in their villages in the intervention 
Table 1 Monthly child food ration supplied in the intervention

\begin{tabular}{lrcc}
\hline Food commodity & $\mathrm{kJ} / \mathrm{d}$ & Food quantity $(\mathrm{g} / \mathrm{d})$ & Total monthly ration \\
\hline Millet & 2109 & 150 & $4500 \mathrm{~g}$ \\
Pigeon peas & 356 & 25 & $750 \mathrm{~g}$ \\
Milk (fresh) & 452 & 125 & $3750 \mathrm{~g}$ \\
Eggs (50 g without shell) & 314 & 50 & $30 \mathrm{eggs}$ \\
Vegetable oil & 377 & 10 & $300 \mathrm{~g}$ \\
Mango & 218 & 100 & 15 (medium size) \\
Sugar & 234 & 15 & $450 \mathrm{~g}$ \\
Total kJ/d & 4058 & & \\
\hline
\end{tabular}

group. They visited the household of these children to obtain consent and measure the child's baseline length/ height and weight. A trained research nurse and assistants carried out anthropometric measurements with the use of standardized methods and instruments. Recumbent length (if $<24$ months) and standing height (if $\geq 24$ months) were measured to the nearest $0 \cdot 1 \mathrm{~cm}$ using a wooden length board for anthropometry measurements. Weight was measured to the nearest $0 \cdot 1 \mathrm{~kg}$ using a hanging Salter scale. Following the collection of anthropometric baseline data in both groups, the first food distribution for the intervention group occurred. Food distribution for the intervention group continued once monthly for 7 months. CHW visited the households of the children in the intervention group monthly to administer a brief survey to assess operational feasibility and effectiveness of supplemental food distribution and utilization.

The non-intervention group was selected and enrolled at the end of the study, and was not monitored monthly. The baseline anthropometric data were available from the malnutrition screening of the non-intervention group that was conducted prior to the start of the intervention. CHW in the villages of the non-intervention group identified children who were 6-20 months of age at the time of the baseline anthropometric data collection, and the same children were weighed and measured, and household survey data collected, at the end of the study. Consent was obtained from the caregiver of the children in the non-intervention group at the end of the study. The only contact with the non-intervention group occurred at the time of collection of baseline anthropometric data and at the time of the end-of-study data collection.

At the conclusion of the study, a survey was administered to the caregiver of each child in both groups in order to obtain data on the demographic, socio-economic and food consumption characteristics of the participants. In addition, a Kikamba-speaking nutritionist collected $24 \mathrm{~h}$ dietary recall data for every child in the intervention and non-intervention groups at the end of the study.

\section{Intervention}

The intervention consisted of the distribution of a monthly food ration for the index child, a separate family ration, and a group education session on appropriate complementary feeding and hygiene. The educational sessions were conducted monthly at the time of the food distribution, with the first session at the time of enrolment into the study. The sessions were brief and not agespecific. The mothers/caregivers of the children were instructed in hand washing and safe food handling and preparation, as well as the importance of feeding the target child a combination of the local foods in order to meet the child's nutritional requirements. The educational counselling on appropriate complementary feeding was based on the WHO guidelines published in the document Guiding Principles for Complementary Feeding of the Breastfed Child $^{(4)}$. The educational sessions were conducted in the local Kikamba language by a research nurse who received training from the district nutrition officer.

The Yatta District Nutrition Officer and an academic nutritionist advised on the amount and content of the food ration. The monthly ration contained local foods to provide the recommended daily energy needs for the upper limit age group (20 months) for complementary feeding. The total daily energy requirement recommended for this group is $4561 \mathrm{~kJ} / \mathrm{d}$ out of which $1423 \mathrm{~kJ} / \mathrm{d}$ should come from breast milk and $3138 \mathrm{~kJ} / \mathrm{d}$ from complementary foods $^{(15)}$. The total daily food ration planned for in the present study was however $4058 \mathrm{~kJ} / \mathrm{d}$, more than the recommended $3138 \mathrm{~kJ} / \mathrm{d}$, to account for losses during preparation and feeding, and the likelihood of intrahousehold sharing of the food ration with other children. Except for the oil and sugar, the selection of all items in the food ration was based on local availability (Table 1).

A family food ration was also distributed monthly, consisting of $14 \mathrm{~kg}$ maize flour and $2 \mathrm{~kg}$ beans. The child and family food ration distribution continued for a total of 7 months (November 2009-May 2010).

Anthropometric measurements were conducted for the intervention group during the course of the study to monitor the nutritional status of the children. Children who had $-3<$ WHZ $<-2$ were given a fortified maizesoya blend flour supplement (Unimix ${ }^{\circledR}$; Techno Relief Services, Nairobi, Kenya). The children who had WHZ $<-3$ were given the ready-to-use therapeutic food (Plumpy'nut ${ }^{\circledR}$; Nutriset, Malaunay, France). The children with wasting continued in the study but were also monitored by the local medical clinic. 


\section{Statistical analysis}

The anthropometric and other data were entered into Epi Info ${ }^{\text {TM }}$ software version 6 (Centers for Disease Control and Prevention, Atlanta, GA, USA), and nutritional status indicators presented as $Z$-scores were computed against the WHO 2006 reference data. Data analysis was completed using the statistical software packages SAS version $9 \cdot 2$ (SAS Institute, Inc., Cary, NC, USA) and STATA version 11 (StataCorp LP, College Station, TX, USA). Since the villages were the primary sampling units, statistical techniques for multilevel sampling were used to compare intervention and non-intervention groups. Mixed-effects models were used for continuous variables such as baseline $Z$-scores, $24 \mathrm{~h}$ nutrient intakes and pre-post changes in $Z$-scores. In addition, adjusted estimates of pre-post $Z$-score changes were calculated from multivariate mixed-effects models using the following covariates: age, gender, respiratory disease, vitamin A, diarrhoea, maternal schooling, occupation, current breast-feeding, outside financial assistance and acres of land used for growing crops. We used $t$ tests for average proportions to compare prevalences of underweight, stunting and wasting between the intervention and non-intervention groups.

The study was planned with an estimated sample size of 200 in each group, yielding $80 \%$ power for detecting a difference between groups of 0.3 in the pre-post changes in mean $Z$-scores. Based on previous surveys, we estimated that the final acute malnutrition rate (weight-forlength $Z$-score $<-2$ ) in the non-intervention group would be $8 \%$, and the point prevalence of diarrhoea was estimated at $10 \%$. The study has the ability to detect a reduction in acute malnutrition from $8 \%$ to $2 \%$, assuming $\alpha$ of 0.05 and power of 0.8 . For diarrhoea prevalence, there is $80 \%$ power to detect a decrease from $10 \%$ to $3 \%$ or an increase from $10 \%$ to $20 \%$. The results for the information on process indicators (amount of supplement delivered, adherence to the supplementation programme, leakage) were calculated as proportions, e.g. proportion of food supplements received in $\mathrm{kg}$ as reported by the mother; proportion of households reporting gaps in delivery; proportion of index children reported as the only person in the household to receive the supplement. With the estimated sample size of 200, and average energy and protein intakes in the non-intervention group of $3347 \mathrm{~kJ} / \mathrm{d}$ and $24 \mathrm{~g} / \mathrm{d}$ respectively, there was $80 \%$ power for detecting a difference of $\pm 209 \mathrm{~kJ} / \mathrm{d}$ for energy and $\pm 2.3 \mathrm{~g} / \mathrm{d}$ for protein. A $P$ value of $<0.05$ was considered to be statistically significant.

\section{Results}

In the intervention group, the final sample size was 129 after exclusions for $\mathrm{WHZ}<-2$, missing data, implausible values and children lost to follow-up. Initial screening by CHW identified 156 children in the intervention sub-location who were 6-20 months of age. After excluding seventeen children with $\mathrm{WHZ}<-2,139$ were enrolled in the intervention group to receive the food supplements. At the end of the study, six children were lost to follow-up, two children were excluded for missing data and two children were excluded for implausible values, leaving a final sample size of 129 for the intervention group. Out of the 129 children in the intervention group, 120 were available to complete the $24 \mathrm{~h}$ nutrition survey.

In the non-intervention group, the final sample size was 147 after exclusions for $\mathrm{WHZ}<-2$, missing data, implausible values and children lost to follow-up. Initial screening by $\mathrm{CHW}$ identified 218 children in the non-intervention sub-location who were 6 months to 20 months of age. After excluding thirty-three children with $\mathrm{WHZ}<-2$, six children with missing anthropometric data and two children with implausible values, 177 children were measured for the baseline anthropometric analysis. At the end of the study, twenty-eight were excluded for missing data and two children were excluded for implausible values, leaving a final sample size of 147 for the non-intervention group. Out of the 147 children in the non-intervention group, 143 completed the $24 \mathrm{~h}$ nutrition study. The children in the intervention and non-intervention groups had similar baseline anthropometric measures as shown in Table 2.

In the final survey both groups had similar child, maternal and household characteristics except for duration of exclusive breast-feeding, number of doses of vitamin $\mathrm{A}$ and acres of land (Table 3). For the children who were lost to follow-up, there were no significant differences in anthropometric measurements at baseline between those in the intervention group and those in the non-intervention group.

\section{Feasibility}

Distribution of food supplements to the intervention group was successful. All households reported receiving food monthly, and families confirmed in the survey that the intended amounts were received. The survey found that for $90 \%$ of the time that the supplementary food was distributed, the caregiver reported that the index child was given at least $50 \%$ of the food. The index child was the only person in the household consuming the milk $79 \%$ of the time and the only person consuming the eggs $78 \%$ of the time. Sharing was greatest with foods such as oil and millet, and was lowest for the eggs and milk. Data from a $24 \mathrm{~h}$ recall, conducted by a Kenyan Kikambaspeaking nutritionist, demonstrated that the children in the intervention group received significantly more energy, protein, fat and carbohydrates than the children in the non-intervention group (Table 4).

\section{Child growth and malnutrition prevalence}

The adjusted and unadjusted group differences in prepost $Z$-score changes between the intervention and 
Table 2 Anthropometric measurements at baseline by group: children aged 6-20 months with $\mathrm{WHZ} \geq-2$, Eastern Province, Kenya, November 2009

\begin{tabular}{|c|c|c|c|c|c|}
\hline \multirow[b]{2}{*}{ Measurement } & \multicolumn{2}{|c|}{$\begin{array}{l}\text { Intervention } \\
\quad(n \text { 129) }\end{array}$} & \multicolumn{2}{|c|}{$\begin{array}{l}\text { Non-intervention } \\
(n 147)\end{array}$} & \multirow[b]{2}{*}{$P$ value } \\
\hline & Mean or prevalence & $95 \% \mathrm{Cl}$ & Mean or prevalence & $95 \% \mathrm{Cl}$ & \\
\hline WAZ* & -0.51 & $-0.70,-0.33$ & -0.37 & $-0.54,-0.21$ & $0 \cdot 26$ \\
\hline$W A Z<-2 \dagger$ & $7 \cdot 0$ & $2 \cdot 2,11 \cdot 8$ & $3 \cdot 8$ & $0 \cdot 0,7 \cdot 2$ & 0.26 \\
\hline $\mathrm{HAZ}^{*}$ & $-1 \cdot 23$ & $-1.50,-0.96$ & $-1 \cdot 21$ & $-1 \cdot 41,-1 \cdot 01$ & 0.91 \\
\hline$H A Z<-2 \dagger$ & $26 \cdot 6$ & $18 \cdot 7,34 \cdot 5$ & $25 \cdot 9$ & $17 \cdot 4,34 \cdot 3$ & 0.90 \\
\hline $\mathrm{WHZ}^{*}$ & $0 \cdot 19$ & $0.03,0.36$ & 0.34 & $0.20,0.48$ & $0 \cdot 15$ \\
\hline $\mathrm{WHZ}<-2 \dagger$ & 0 & & 0 & & - \\
\hline
\end{tabular}

WAZ, weight-for-age $Z$ score; $\mathrm{HAZ}$, height-for-age Z-score; $\mathrm{WHZ}$, weight-for-height $Z$-score.

${ }^{\star}$ Data are presented as mean and $95 \%$ confidence interval.

tData are presented as prevalence (\%) and $95 \%$ confidence interval.

Table 3 Selected demographic and socio-economic characteristics of the children and households who completed the study by group: Eastern Province, Kenya, May 2010

\begin{tabular}{|c|c|c|c|c|c|}
\hline & \multicolumn{2}{|c|}{$\begin{array}{l}\text { Intervention } \\
(n \text { 129) }\end{array}$} & \multicolumn{2}{|c|}{$\begin{array}{l}\text { Non-intervention } \\
(n 147)\end{array}$} & \multirow[b]{2}{*}{$P$ value } \\
\hline & Mean or proportion & $95 \% \mathrm{Cl}$ & Mean or proportion & $95 \% \mathrm{Cl}$ & \\
\hline \multicolumn{6}{|l|}{ Child characteristics } \\
\hline Age at baseline (months)* & $14 \cdot 0$ & $13 \cdot 1,14 \cdot 9$ & $13 \cdot 2$ & $12 \cdot 3,14 \cdot 0$ & $0 \cdot 15$ \\
\hline Malet & $47 \cdot 8$ & $37 \cdot 4,58 \cdot 3$ & $50 \cdot 5$ & $40 \cdot 7,60 \cdot 2$ & $0 \cdot 70$ \\
\hline Birth weight $(\mathrm{kg})^{*} \ddagger$ & $3 \cdot 2$ & $2 \cdot 9,3 \cdot 4$ & $3 \cdot 4$ & $3 \cdot 1,3 \cdot 7$ & $0 \cdot 11$ \\
\hline Currently breast-feedingt & $66 \cdot 3$ & $53 \cdot 9,78 \cdot 7$ & $62 \cdot 0$ & $51 \cdot 8,72 \cdot 1$ & 0.57 \\
\hline Exclusively breast-fed (months) ${ }^{*}$ & $4 \cdot 8$ & $4 \cdot 4,5 \cdot 3$ & 3.8 & $3 \cdot 5,4 \cdot 1$ & $<0.001$ \\
\hline Received vitamin At & $70 \cdot 5$ & $57 \cdot 6,83 \cdot 3$ & $41 \cdot 4$ & $28 \cdot 8,54 \cdot 1$ & 0.002 \\
\hline \multicolumn{6}{|l|}{ Household characteristics } \\
\hline Number of people* & $6 \cdot 4$ & $5 \cdot 9,6 \cdot 8$ & $6 \cdot 5$ & $6 \cdot 1,6 \cdot 9$ & 0.60 \\
\hline \multicolumn{6}{|l|}{ Occupation, head of householdt } \\
\hline Farming & $39 \cdot 7$ & $25 \cdot 4,54 \cdot 1$ & $35 \cdot 3$ & $24 \cdot 0,46 \cdot 6$ & 0.35 \\
\hline Trade/market & $8 \cdot 1$ & $2 \cdot 7,13 \cdot 6$ & $10 \cdot 8$ & $4 \cdot 2,17 \cdot 4$ & 0.52 \\
\hline Unemployed & $23 \cdot 9$ & $16 \cdot 5,31 \cdot 3$ & $19 \cdot 8$ & $12 \cdot 5,27 \cdot 2$ & $0 \cdot 42$ \\
\hline Other & $28 \cdot 2$ & $17 \cdot 2,39 \cdot 2$ & $34 \cdot 1$ & $23 \cdot 3,44 \cdot 8$ & 0.43 \\
\hline Outside financial assistancet & $25 \cdot 9$ & $15 \cdot 4,36 \cdot 4$ & $33 \cdot 3$ & $21 \cdot 1,45 \cdot 6$ & 0.34 \\
\hline Ever attended school, caregivert & $98 \cdot 1$ & $95 \cdot 8,100 \cdot 0$ & $96 \cdot 6$ & $93 \cdot 7,99 \cdot 6$ & 0.51 \\
\hline Years of school* & $7 \cdot 8$ & $7 \cdot 3,8 \cdot 3$ & 8.0 & $7 \cdot 6,8 \cdot 3$ & 0.58 \\
\hline \multicolumn{6}{|l|}{ Household amenitiest } \\
\hline Electricity & $1 \cdot 8$ & $0 \cdot 0,5 \cdot 3$ & 0.0 & $0 \cdot 0,2 \cdot 4$ & $0 \cdot 15$ \\
\hline Tap water & $0 \cdot 8$ & $0 \cdot 0,2 \cdot 6$ & $0 \cdot 0$ & $0 \cdot 0,2 \cdot 4$ & $0 \cdot 30$ \\
\hline Latrine or toilet & $96 \cdot 1$ & $92 \cdot 1,100 \cdot 0$ & 94.9 & $91 \cdot 1,98 \cdot 6$ & 0.64 \\
\hline \multicolumn{6}{|l|}{ Agricultural characteristics } \\
\hline Grow crops or raise livestockt & $100 \cdot 0$ & $97 \cdot 2,100 \cdot 0$ & $99 \cdot 3$ & $97 \cdot 9,100 \cdot 0$ & 0.32 \\
\hline Acres of land* & $5 \cdot 7$ & $5 \cdot 1,6 \cdot 3$ & $4 \cdot 6$ & $4 \cdot 0,5 \cdot 3$ & 0.03 \\
\hline Acres for growing crops* & $2 \cdot 9$ & $2 \cdot 7,3 \cdot 2$ & $2 \cdot 4$ & $2 \cdot 1,2 \cdot 6$ & 0.003 \\
\hline Number of chickens ${ }^{*}$ & $8 \cdot 2$ & $7 \cdot 1,9 \cdot 2$ & $9 \cdot 3$ & $8 \cdot 2,10 \cdot 4$ & $0 \cdot 15$ \\
\hline Number of goats* & $6 \cdot 1$ & $5 \cdot 2,7 \cdot 1$ & $7 \cdot 5$ & $6 \cdot 2,8 \cdot 8$ & $0 \cdot 10$ \\
\hline Number of cattle* & $0 \cdot 8$ & $0 \cdot 6,1 \cdot 1$ & $1 \cdot 1$ & $0 \cdot 8,1 \cdot 4$ & $0 \cdot 15$ \\
\hline
\end{tabular}

*Data are presented as geometric mean and $95 \%$ confidence interval.

tData are presented as proportion (\%) and $95 \%$ confidence interval.

¥Sample sizes are $n 20$ for the intervention group and $n 19$ for the non-intervention group.

non-intervention groups are shown in Table 5. The 'intervention effect' listed in Table 5 is the difference between the groups in the change in mean $Z$-score over the 7-month intervention period. There were significant differences in the intervention effect for weight-for-age and weight-forheight, but not for height-for-age. The differences between the groups remained significant after adjusting for age, gender, respiratory disease, vitamin A, diarrhoea, maternal schooling, occupation, current breast-feeding, outside financial assistance and land used for growing crops.
Malnutrition prevalence is shown in Table 6. The prevalence of wasting was significantly lower in the intervention group (0\%) than the non-intervention group (8.9\%, $P=0 \cdot 0002)$. Significantly fewer children were underweight in the intervention group than the non-intervention group $(6 \cdot 3 \% v \cdot 23 \cdot 0 \%, P<0 \cdot 0001)$. No significant difference was found for growth stunting.

The intervention group of children was monitored for wasting with weight and length measurements on four occasions during the study. The non-intervention group 
Table 4 Nutrient intakes from $24 \mathrm{~h}$ recall at end of the study by group: children aged 6-20 months and with WHZ $\geq-2$ at baseline, Eastern Province, Kenya, May 2010

\begin{tabular}{|c|c|c|c|c|c|}
\hline \multirow[b]{2}{*}{ Nutrient } & \multicolumn{2}{|c|}{$\begin{array}{l}\text { Intervention } \\
(n 120)^{\star}\end{array}$} & \multicolumn{2}{|c|}{$\begin{array}{l}\text { Non-intervention } \\
(n \text { 143 }) \dagger\end{array}$} & \multirow[b]{2}{*}{$P$ value } \\
\hline & Mean & $95 \% \mathrm{Cl}$ & Mean & $95 \% \mathrm{Cl}$ & \\
\hline Total energy $(\mathrm{kJ} / \mathrm{d})$ & 3612 & 3473,3750 & 2559 & 2437, 2681 & $<0.001$ \\
\hline Protein $(\mathrm{g} / \mathrm{d})$ & $31 \cdot 2$ & $29 \cdot 6,32 \cdot 7$ & $19 \cdot 4$ & $18 \cdot 3,20 \cdot 6$ & $<0.001$ \\
\hline Fat $(g / d)$ & $26 \cdot 0$ & $24 \cdot 2,27 \cdot 9$ & $15 \cdot 2$ & $14 \cdot 0,16 \cdot 3$ & $<0.001$ \\
\hline Carbohydrates (g/d) & $126 \cdot 1$ & $120 \cdot 8,131 \cdot 3$ & $99 \cdot 2$ & $93 \cdot 8,104 \cdot 7$ & $<0.001$ \\
\hline
\end{tabular}

*In the intervention group, nine of 129 children had missing dietary data.

tIn the non-intervention group, four of 147 children had missing dietary data.

Table 5 Effect of the intervention on child growth: group differences in pre-post Z-score changes, Eastern Province, Kenya, November 2009-May 2010

\begin{tabular}{|c|c|c|c|c|c|c|c|c|c|c|}
\hline \multirow[b]{3}{*}{ Measurement } & \multicolumn{4}{|c|}{ Pre-post change } & \multicolumn{5}{|c|}{ Intervention effect } & \multirow[b]{3}{*}{$P$ value } \\
\hline & \multicolumn{2}{|c|}{ Intervention } & \multicolumn{2}{|c|}{ Non-intervention } & \multicolumn{2}{|c|}{ Unadjusted } & \multirow[b]{2}{*}{$P$ value } & \multicolumn{2}{|c|}{ Adjusted* } & \\
\hline & Z-score & $\mathrm{SE}$ & Z-score & $\mathrm{SE}$ & Z-score & $\mathrm{SE}$ & & Z-score & $\mathrm{SE}$ & \\
\hline Weight-for-age & 0.03 & 0.05 & -0.82 & 0.05 & 0.79 & 0.07 & $<0.001$ & $0 \cdot 82$ & 0.07 & $<0.001$ \\
\hline Height-for-age & $-0 \cdot 47$ & 0.09 & -0.32 & 0.06 & $-0 \cdot 15$ & $0 \cdot 11$ & $0 \cdot 18$ & $-0 \cdot 20$ & $0 \cdot 12$ & 0.09 \\
\hline Weight-for-height & $0 \cdot 19$ & $0 \cdot 11$ & -0.92 & 0.07 & $1 \cdot 14$ & $0 \cdot 12$ & $<0.001$ & $1 \cdot 19$ & $0 \cdot 13$ & $<0.001$ \\
\hline
\end{tabular}

*Adjusted for age, gender, respiratory disease, vitamin A, diarrhoea, maternal schooling, occupation, current breast-feeding, outside financial assistance and land used for growing crops.

Table 6 Malnutrition prevalence at end of the intervention by group: children aged 6-20 months and with WHZ $\geq-2$ at baseline, Eastern Province, Kenya, May 2010

\begin{tabular}{|c|c|c|c|c|c|}
\hline \multirow[b]{2}{*}{ Measurement } & \multicolumn{2}{|c|}{$\begin{array}{l}\text { Intervention } \\
(n \text { 129) }\end{array}$} & \multicolumn{2}{|c|}{$\begin{array}{l}\text { Non-intervention } \\
(n 147)\end{array}$} & \multirow[b]{2}{*}{$P$ value } \\
\hline & Prevalence (\%) & $95 \% \mathrm{Cl}$ & Prevalence (\%) & $95 \% \mathrm{Cl}$ & \\
\hline Underweight (WAZ <-2) & $6 \cdot 3$ & $1 \cdot 2,11 \cdot 4$ & $23 \cdot 0$ & $14 \cdot 1,32 \cdot 0$ & 0.002 \\
\hline Stunting $(\mathrm{HAZ}<-2)$ & $37 \cdot 2$ & $28 \cdot 7,45 \cdot 8$ & $35 \cdot 0$ & $27 \cdot 0,43 \cdot 1$ & 0.69 \\
\hline Wasting $(\mathrm{WHZ}<-2)$ & $0 \cdot 0$ & $0 \cdot 0,2 \cdot 8$ & $8 \cdot 9$ & $4 \cdot 3,13 \cdot 4$ & $<0.001$ \\
\hline
\end{tabular}

WAZ, weight-for-age Z-score; HAZ, height-for-age Z-score; WHZ, weight-for-height Z-score.

was not monitored; those children were enrolled in the study at the end of the intervention period, and the baseline anthropometric data used were data collected in a malnutrition screening programme underway when the study was initiated. Of the 129 children in the intervention group, thirteen of them were enrolled briefly in the therapeutic programme for acute malnutrition (wasting). For twelve of those thirteen children the therapeutic feeding was initiated because of an error by the CHW; they did not have a WHZ $<-2$. They received only one week of therapeutic food (Plumpy'nut for one child and Unimix for eleven children). One child was found to be wasted and was given one week of Plumpy'nut, then was lost to follow-up until the final survey. When the thirteen children who received the Plumpy'nut or Unimix supplementation were compared with the 116 children who did not receive the supplements, there was no significant difference in pre-post $Z$-score changes for weight-forage, weight-for-height or height-for-age.

\section{Infectious morbidity}

Table 7 shows diarrhoeal and respiratory infection rates (as point prevalence) in the intervention and control groups. When compared at final survey, there was no significant difference between the children in the intervention group and the non-intervention group.

\section{Discussion}

The present study demonstrates that, in rural Kenyan villages with a high prevalence of malnutrition, a supplementary feeding programme based on locally produced foods, combined with brief group nutrition education sessions, is feasible and effective in improving weight gain and in the prevention of wasting in young children. Operational feasibility was demonstrated from the monthly surveys and observation of the distribution process. As anticipated, food was being shared with other 
Table 7 Comparison of infection prevalence at the final survey by group: children aged 6-20 months and with WHZ $\geq-2$ at baseline, Eastern Province, Kenya, May 2010

\begin{tabular}{|c|c|c|c|c|c|}
\hline \multirow[b]{2}{*}{ Infection } & \multicolumn{2}{|c|}{ Intervention ( $n$ 129) } & \multicolumn{2}{|c|}{ Non-intervention ( $n$ 147) } & \multirow[b]{2}{*}{$P$ value } \\
\hline & Prevalence (\%) & $95 \% \mathrm{Cl}$ & Prevalence (\%) & $95 \% \mathrm{Cl}$ & \\
\hline Diarrhoea & $17 \cdot 6$ & $9 \cdot 9,25 \cdot 3$ & $16 \cdot 2$ & $10 \cdot 6,21 \cdot 8$ & 0.76 \\
\hline Respiratory & $2 \cdot 7$ & $0 \cdot 0,6 \cdot 8$ & $6 \cdot 6$ & $2 \cdot 6,11 \cdot 5$ & $0 \cdot 18$ \\
\hline
\end{tabular}

family members, mostly other children. The aspect of intra-household sharing of food was taken into consideration in the intervention design, which allowed for an extra $920 \mathrm{~kJ} / \mathrm{d}$ per study child. Despite the leakage of the supplements, the index child received a sufficient amount of the food to significantly improve nutrient intake and prevent the development of wasting.

The supplemented group was found to have significantly better growth and less malnutrition than the non-intervention group as measured by weight change. The nutritional status indicators of the children in the non-intervention group deteriorated significantly. The supplemented group maintained weight-for-age and weight-for-length $Z$-scores during the 7-month study period. There were some differences in the characteristics of the two groups, but our analysis found no relationship of those characteristics and child growth or malnutrition prevalence. Thirteen of the children in the intervention group briefly received therapeutic feeding in addition to the food supplements, but the 1 week of therapeutic food did not significantly influence the overall results.

There was a substantial decline in height-for-age $Z$-score in the intervention group as well as the nonintervention group. The most likely explanation for the lack of linear growth improvement is that the intervention period was too short for the intervention to have an impact on growth in stature for the children. A contributing factor was the age of the children when the intervention started. Although the study was planned with the intent to intervene as early as possible after weaning foods are introduced, the mean age at study entry was 14 months in the intervention group and the prevalence of growth stunting was already $27 \%$. Other investigators have found improvements in linear growth only in the youngest children in their nutrition and education interventions ${ }^{(16,17)}$. This is an issue that requires further study.

Most studies of supplementary feeding and child malnutrition have used commercially prepared products that are distributed to the mothers or caregivers. Most have included malnourished children in their sample and studied treatment rather than prevention. In one of the few published prevention studies, Ruel et al. ${ }^{(18)}$ compared a 'preventive model' that provided fortified wheat-soya supplements to all children 6 to 23 months of age with a 'recuperative' model that targeted underweight children 6-59 months of age in Haiti. The preventive model was found to reduce stunting, wasting and underweight at age 3 years by $4-6$ percentage points compared with the recuperative model. The preventive model group included children with malnutrition, with a prevalence of wasting of $5 \cdot 2 \%$ at baseline. Our study excluded children with wasting at baseline and studied its prevention with locally available foods. Project Poshak in India was one of the few attempts to investigate in a controlled study the feasibility and effectiveness of the distribution of local foods ${ }^{(19)}$. No significant difference was found in the final weight of the children in the supplemented group compared with a group of age-matched controls. The low participation rate in that project was a likely explanation for the lack of benefit. 'Leakage' or sharing of food with other family members is a recognized problem when familiar locally available foods are distributed ${ }^{(20)}$. A study of a milk distribution programme in Brazil found that leakage was the probable reason for lack of improvement in nutrition outcomes for the supplemented children ${ }^{(10)}$. The low leakage likely contributed to the positive results in our study.

There are weaknesses of the study that should be mentioned. The quasi-experimental design is open to bias from confounding variables, some of which may not have been identified. This design was chosen due to ethical concerns of community leaders that randomization of villages into a control group that would be denied food distribution would be unacceptable. Although a randomized design was not used, our study can be considered a plausibility evaluation in that a reasonable comparison group was chosen with control for confounding variables $^{(21)}$. The location for the intervention group was chosen because of local interested and motivated governmental and medical personnel, which may decrease the applicability of our results to other settings.

We can plausibly conclude that the distribution of locally available foods is a feasible and effective approach to the prevention of acute child malnutrition in certain settings. The observed significant difference in daily intake of all nutrients by the intervention group compared with the control group was mainly attributed to the food supplement that the intervention group received. However, just like other supplementary feeding and food aid programmes, this can only be a temporary measure for the prevention of child malnutrition. This alternative to commercially prepared products has greater potential for sustainability only if adequate local production and availability are achievable. It remains to be seen, however, if the poorest in a community are able to continue 
the use of the high-quality foods used in our study after free distribution has ended. Our results suggest that development efforts to increase local production of certain foods, combined with an education programme, may be a useful approach for prevention of the highly prevalent problem of child malnutrition.

\section{Acknowledgements}

Sources of funding: The study was supported by a University of New Mexico School of Medicine Research Allocation Committee Grant as well as funds from Global Health Partnerships. Conflict of interest declaration: A.T. is President of Global Health Partnerships. F.R.-M., K.M., R.A., R.O. and M.M. report no conflicts of interest. Authorship responsibilities: A.T. conceived the study hypothesis, supervised the participation of other investigators in the study, and wrote parts of the manuscript; F.R.-M. wrote sections of the manuscript and participated in discussions about data analysis; R.A. and K.M. participated in the implementation of the study in Kenya, participated in data entry and data analysis, and wrote sections of the manuscript; R.O. served as the nutritionist for the study in Kenya; M.M. coordinated the study in Kenya. Acknowledgments: The authors acknowledge the important contributions of Nicholas Mutuku who coordinated the surveys in Kenya; Susan Kivaya, the Yatta District Nutrition Officer, and other members of the Yatta District Health Management Team. Dr Betty Skipper and Cheryl Schmitt provided valuable statistical support.

\section{References}

1. Black RE, Allen LH, Bhutta ZA et al. (2008) Maternal and child undernutrition: global and regional exposures and health consequences. Lancet 371, 243-260.

2. Kenya National Bureau of Statistics \& ICF Macro (2010) Kenya Demographic and Health Survey 2008-2009. Calverton, MD: KNBS and ICF Macro; available at http:// www.measuredhs.com/pubs/pdf/FR229/FR229.pdf

3. Bwibo NO \& Neumann CG (2003) The need for animal source foods by Kenyan children. J Nutr 133, Suppl. 2, 3936S-3940S

4. Pan American Health Organization \& World Health Organization (2003) Guiding Principles for Complementary Feeding of the Breastfed Child. Washington, DC: PAHO and WHO; available at http://www.who.int/child_adolescent_ health/documents/a85622/en

5. USAID Food for Peace (2009) What is food for peace? http://www.usaid.gov/our_work/humanitarian_assistance/ffp/ (accessed September 2010).
6. Beaton G \& Ghassemi H (1982) Supplementary feeding programs for young children in developing countries. Am J Clin Nutr 34, 864-916.

7. World Bank (2005) The Bangladesh Integrated Nutrition Project. Effectiveness and Lessons. Dhaka: The World Bank Office; available at http://siteresources.worldbank.org/ NUTRITION/Resources/BNGBINP8.pdf

8. Save the Children (2003) Thin on the Ground. Questioning the Evidence Behind World Bank-Funded Community Nutrition Projects in Bangladesh, Ethiopia and Uganda. London: Save the Children; available at http://www. savethechildren.org.uk/en/54_5214.htm

9. Dewey KG \& Adu-Afarwuah S (2008) Systematic review of the efficacy and effectiveness of complementary feeding interventions in developing countries. Matern Child Nutr 4, Suppl. 1, 24-85.

10. Santos IS, Gigante DP, Coitinho DC et al. (2005) Evaluation of the impact of a nutritional program for undernourished children in Brazil. Cad Saude Publica 21, 776-778.

11. Hakim P \& Solimano G (1978) Development, Reform and Malnutrition in Chile. Cambridge, MA: MIT Press.

12. Grantham-McGregor SM, Fernald LC \& Sethuraman K (1999) Effects of health and nutrition on cognitive and behavioral development in children in the first three years of life. Part 1: Low birthweight, breastfeeding, and proteinenergy undernutrition. Food Nutr Bull 20, 53-75.

13. Martorell R (1995) The effects of improved nutrition in early childhood: the INCAP follow-up study. J Nutr $\mathbf{1 2 5}$, Suppl. 4, 1027S-1038S.

14. Engle PL, Black MM, Behrman JR et al. (2007) Strategies to avoid the loss of developmental potential in more than 200 million children in the developing world. Lancet 369, 229-242.

15. Sanghvi T (1999) Nutrition Essentials - A Guide for Health Managers, p. 22. New York: World Health Organization/ BASICS Project/UNICEF; available at http://www.basics.org/ documents/pdf/NutritionEssentials_English.pdf

16. Rivera JA, Sotres-Alvarez D, Habicht JP et al. (2004) Impact of the Mexican program for education, health, and nutrition (Progresa) on rates of growth and anemia in infants and young children: a randomized effectiveness study. JAMA 291, 2563-2570.

17. Schroeder DG, Pachon H, Dearden KA et al. (2002) An integrated child nutrition intervention improved growth of younger, more malnourished children in northern Viet Nam. Food Nutr Bull 23, 53-61.

18. Ruel MT, Menon P, Habicht JP et al. (2008) Age-based preventive targeting of food assistance and behaviour change and communication for reduction of childhood undernutrition in Haiti: a cluster randomised trial. Lancet 371, 588-595.

19. Gopaldas T, Srinivasan N, Varadarajan I et al. (1975) In Project Poshak: An Integrated Health-Nutrition Macro Pilot Study for Preschool Children in Rural and Tribal Madbya Pradesh, vol. 1 and 2. New Delhi: CARE-India.

20. Beaton GH \& Ghassemi H (1982) Supplementary feeding programs for young children in developing countries. $\mathrm{Am} \mathrm{J}$ Clin Nutr 35, Suppl. 4, 863-916.

21. Victora C, Habicht J-P \& Bryce J (2004) Evidence-based public health: moving beyond randomized trials. $\mathrm{Am} \mathrm{J}$ Public Health 94, 400-405. 